\title{
8
}

\section{Analysis of SSO Control Alternatives within the City of Detroit's Regional Collection System}

\author{
Michael Taylor, Philip Brink and Marc Stonehouse
}

A number of Detroit Water and Sewerage Department's (DWSD) wholesale customers experience effects of sanitary sewer overflows (SSO), including basement flooding. As part of DWSD's wastewater master plan (WWMP) project, the city has investigated various local and regional alternatives for SSO control.

SSOs, releases of untreated sewage into the environment, are illegal in Michigan. Related to basement flooding, SSOs have the potential to cause property damage and may present public health concerns. The Michigan Department of Environmental Quality (MDEQ) policy is to identify sanitary sewer overflows, and take appropriate action to eliminate them.

Several customers approached DWSD to request additional contract capacity as an approach for eliminating SSOs in their collection system, and in spring of 2001, DWSD and its customers began a collaborative process to examine solutions to eliminate the public health and water quality impacts of SSOs in the regional collection system. The purpose of this study was to find a cost-effective solution for SSO elimination in the service area. The following alternatives were evaluated:

- elimination of the sources of high infiltration/inflow (I/I) that cause SSOs,

- local storage or treatment of SSOs, and

- regional transmission, storage, and treatment of SSOs.

\footnotetext{
Taylor, M., P. Brink and M.C. Stonehouse. 2004. "Analysis of SSO Control Alternatives within the City of Detroit's Regional Collection System." Journal of Water Management Modeling R220-08. doi: 10.14796/JWMM.R220-08.

(C) CHI 2004 www.chijournal.org ISSN: 2292-6062 (Formerly in Innovative Modeling of Urban Water Systems. ISBN: 0-9683681-9-0)
} 


\subsection{Introduction}

\subsubsection{City of Detroit's Regional Collection System}

The city of Detroit provides regional wastewater collection and treatment services for Detroit and 77 communities in the city's metropolitan area. The regional collection and treatment system serves approximately 3 million people over an area of more than 800 square miles $\left(2067 \mathrm{~km}^{2}\right)$. The regional sewer system consists of approximately $220 \mathrm{sq}$. mi. $\left(568 \mathrm{~km}^{2}\right)$ of combined sewers and more than $580 \mathrm{sq} . \mathrm{mi}$. (1498 $\left.\mathrm{km}^{2}\right)$ of separated sanitary sewers.

Detroit's sewer system is nearly all a combined system, and thus the city itself does not experience SSOs. However, several of the city's suburban wholesale customers do have separate sanitary sewer systems that experience SSOs, and these SSOs are caused by a number of factors, including high wet weather flows due to infiltration and inflow; physical capacity limitations; constraints in achieving contract flow capacities to the DWSD system; and temporary operation and maintenance problems. A map of the system that shows the combined and separated sewer service area is provided in Figure 8.1.

Wastewater is treated at the city's wastewater treatment plant (WWTP) located in Detroit. The DWSD constructs, finances, operates, and maintains the system-wide wastewater collection and treatment facilities. Each community owns, operates, and maintains its local collection system (some by contract with a county agency).

\subsubsection{State Regulatory Framework}

The state regulatory agency, MDEQ, adopted its SSO regulations, titled Strategy for the Regulatory Control and Correction of Illegal Overflows from Separate Sanitary Sewer Systems in Michigan on July 10, 2000. MDEQ's goal with promulgating state SSO regulations is to determine separate sanitary sewer overflow discharges in Michigan and take appropriate regulatory and legal actions to eliminate all identified overflows. An update to these regulations issued December 2002 defines the 25-y, 24-h storm as the design event for which all sanitary sewer systems in Michigan should be able to handle without having an SSO.

\subsubsection{SSO Control Analysis Main Elements}

The DWSD WWMP regional SSO control analysis comprises 7 main elements. 


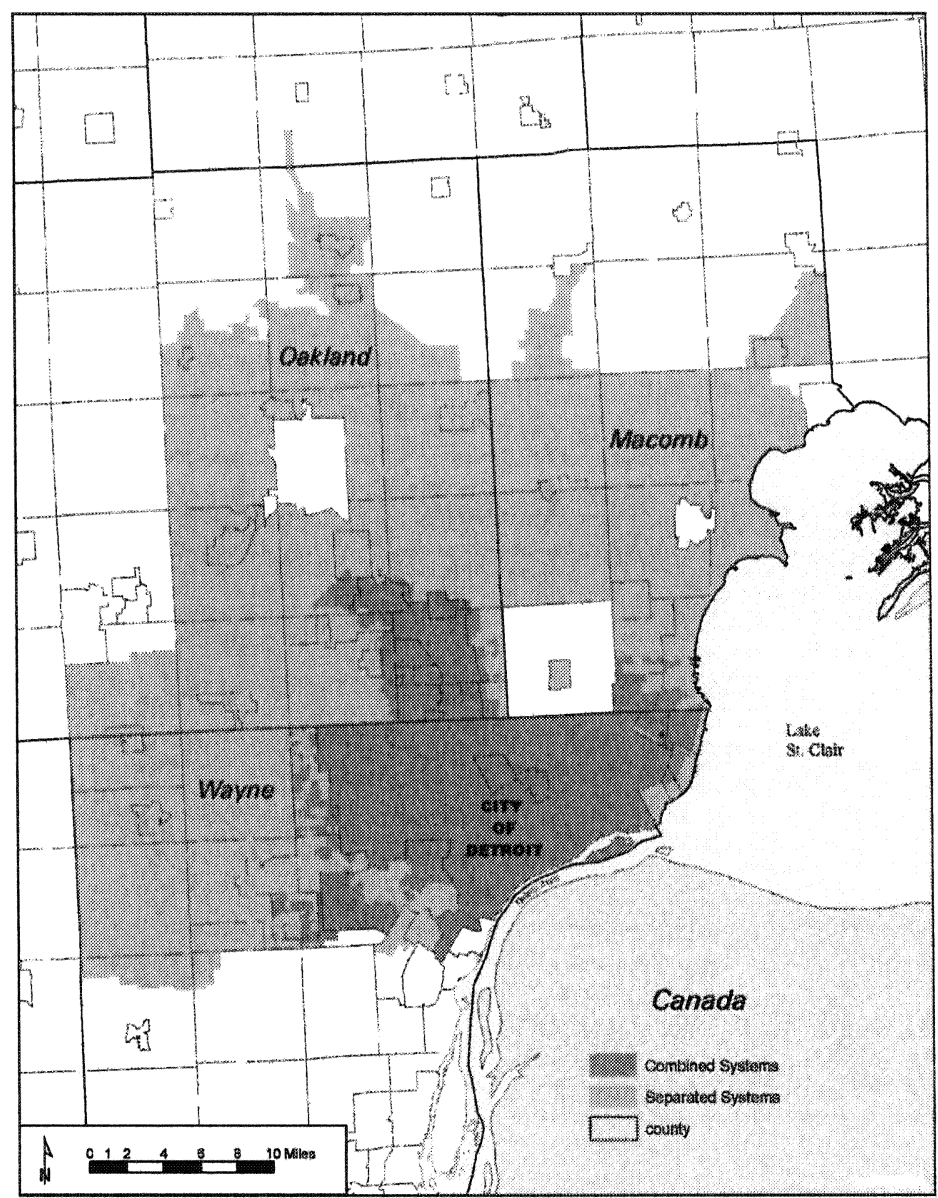

Figure 8.1 City of Detroit's regional collection system.

Establish a Forum. In an effort to use a collaborative approach to this study, the DWSD convened a technical work group representing wholesale customers with SSOs, DWSD staff, WWMP consultants, and the Southeast Michigan Council of Governments (SEMCOG), which is a regional planning agency.

Work with the Regulatory Agency. The SSO strategy established by MDEQ has led to many communities being required to eliminate SSOs within a short timeframe. However, there are still many unanswered questions regarding SSO control and how to implement it cost effectively. With this 
project, DWSD has been active in bringing local concerns and ideas to the MDEQ in order to help establish criteria and timelines for compliance. Future federal regulations proposed by the U.S. Environmental Protection Agency (EPA) also will be taken into account.

Characterize Regional SSO Issues. The analysis identified all known dry and wet weather SSO locations and volumes over the past year, determined the potential water quality impacts on the receiving waters in the region due to SSOs, and classified the likely causes of SSOs in the study area. This information is being used to help prioritize alternatives and timelines based on water quality impacts and costs.

Characterize Local SSO Issues. For this project, six case study communities were selected for evaluation in greater detail. Each one was characterized for SSO location and frequency, causes, tributary area, pathways, and steps taken to reduce or eliminate SSOs.

Collect/Review Field Data. Existing local and regional field monitoring data was reviewed and summarized. This includes collection system flow monitoring, rainfall data, and footing drain flow measurements. This data was used to develop wet weather response parameters and estimate SSO volumes for different design storm events.

Develop Modeling Tools. A regional model of the DWSD service area was updated as part of the wastewater master plan. This model uses the EPA's Storm Water Management Model (SWMM). Local SWMM models for six case study communities were created and linked to the regional model as well.

Conduct Alternative Analyses. The local models and the regional model were used to analyze potential local and regional solutions. Local alternatives include source reduction, storage basins, and local treatment. Regional solutions include increasing transport and contract capacity into the regional system, using existing and proposed storage basins and tunnels, and routing wet weather flows to neighboring collections systems. Planning level costs have been developed for both local and regional alternatives.

\subsection{SSO Characterization}

\subsubsection{Overview}

Characterization of SSOs in the DWSD service area included an understanding of their causes, frequency, volumes, and impacts. Michigan law requires the reporting of SSO events within $24 \mathrm{~h}$ of the start of the overflow. This 
information, beginning July 1, 1999, is available through the MDEQ Web site, $<h t t p: / / w w w . d e q . s t a t e . m i . u s / c s o s s o />$, and was used as the basis for much of the regional characterization. The work group developed a complete list of all reported SSOs in the DWSD service area. The list includes the responsible entity, location, estimated volume, and classification of being either a wet or dry weather SSO. Wet weather SSOs include associated rainfall amounts, and dry weather SSOs include the cause, if known.

One of the main causes of wet weather SSOs is rain-dependent inflow and infiltration (RDII). A major source of RDII are footing drain connections to the santiary sewer system. In the DWSD service area it is suspected that footing drains are a leading contributor to RDII. Footing drains are constructed around the foundations of homes and other buildings with basements to drain water away from basement walls. This is done in order to keep water from leaking through the walls. Water around basement walls can be due to a high groundwater table that may fluctuate seasonally, or due to rainwater that infiltrates into the soil after a rain event. Foundations built in clay with sand backfill can act as a bathtub, not allowing water to disperse through the clay away from the foundation. The timeframe for rain water entering the sanitary system through footing drains can be as short as 5 or $10 \mathrm{~min}$ and as long as 10 days, depending on site and soil conditions.

Historically, the connection of footing drains into sanitary collection systems was common practice in southeast Michigan. Over the years, building code requirements have evolved, and today, footing drains cannot be connected to sanitary collection systems for newly constructed buildings. Prior to 1973 the connection of footing drains was allowable under the National Building Code and few communities had local requirements prohibiting connection to the sanitary system. Between 1973 and 1985, the connection of footing drains to sanitary collection systems was prohibited by individual community ordinances, but enforcement of this building code provision was not widespread. Post- 1985 construction is assumed not to have footing drains connected to the sanitary system.

In locations where combined sewer systems were originally built, all sanitary and storm drainage was directed into a common sewer. In response to combined sewer overflow (CSO) regulations, combined collection systems have been separated in some communities. However, in these instances, footing drains were not typically disconnected from the sanitary system due to the expense and disruption to private property, which would have required redirecting footing drain flow to storm water collection systems or into backyards. 
In order to assess the extent of footing drain connections in the DWSD service area, a map was created that identifies the areas containing a high proportion of residences with footing drains connected to the sanitary system. The map is shown in Figure 8.2. Areas that were identified as not having footing drains connected to the sanitary systems are also shown. Approximately 172,000 , or $24 \%$, of homes with separate sanitary sewers in the DWSD service area have footing drains connected to the sanitary sewer.

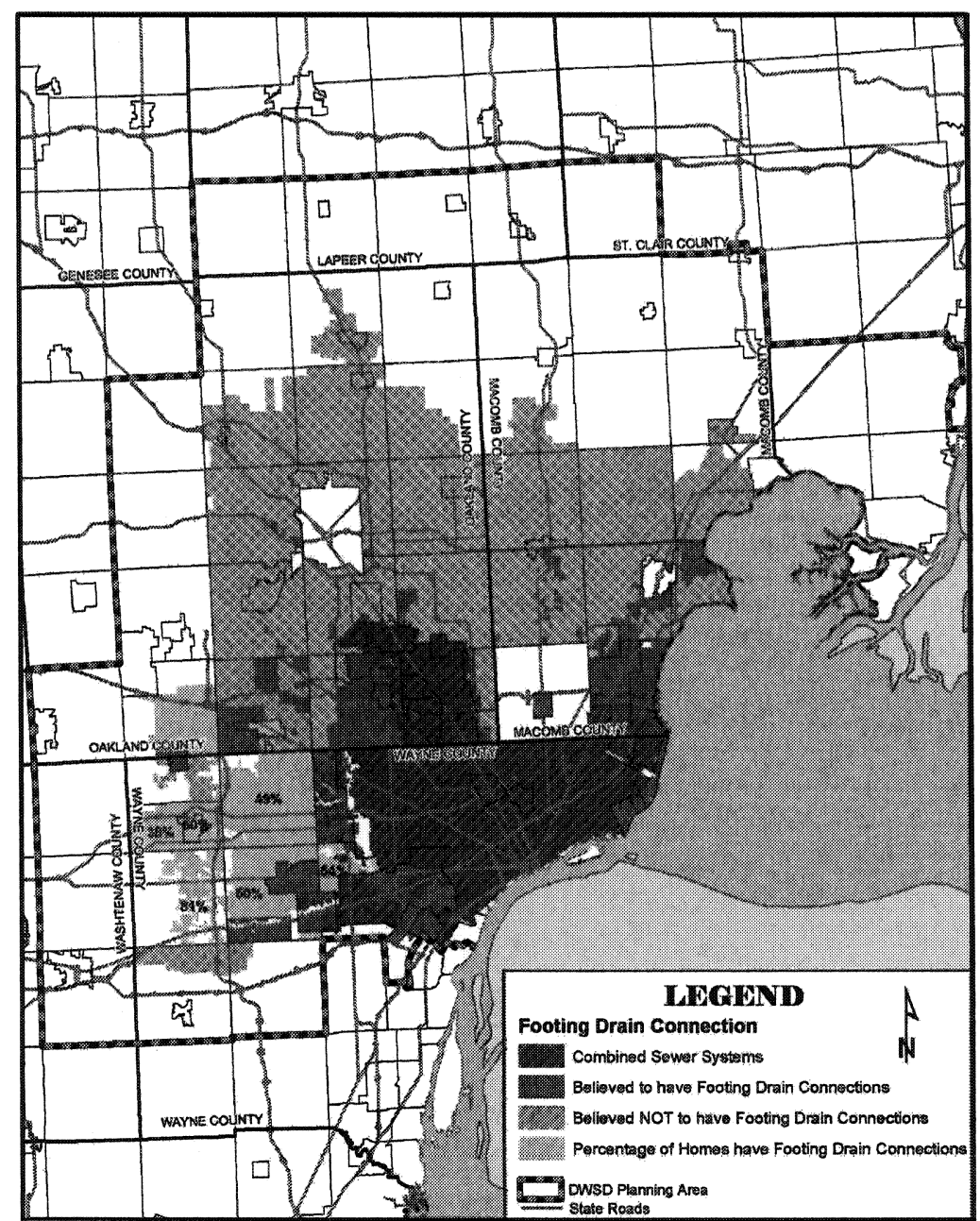

Figure 8.2 Footing drains connections in the DWSD service area. 
Annual total volumes for years 2000 and 2001 of wastewater treated at the Detroit WWTP, CSOs, and SSOs using recent data are compared in Table 8.1. Estimated SSO volumes in the service area were $0.016 \%$ of the volume treated at the Detroit WWTP. The total CSO volume in the service area was $6.2 \%$ of the volume at the treatment plant.

Table 8.1 Comparison of WWTP, CSO, and SSO annual discharge volumes (years 2000 to 2001).

\begin{tabular}{lcc}
\hline \multicolumn{1}{c}{ Source } & Volume (MG) & Percent of WWTP Flow \\
\hline WWTP & 252,478 & 100 \\
SSOs* & 39.3 & 0.016 \\
CSOs (Treated)* & 1,839 & 0.7 \\
CSOs (Untreated)* & 13,798 & 5.5 \\
CSOs (Total)* & 15,637 & 6.2 \\
\hline
\end{tabular}

*As estimated and reported by local communities

\subsubsection{Case Studies}

Six local municipalities volunteered to serve as case studies for a more in-depth investigation to evaluate the cost-effectiveness of three types of solutions:

- local removal of $I / I$ sources to eliminate SSOs,

- local storage and/or treatment, and

- regional transport, storage and treatment.

Results and finding from these six case studies will be available to assist other SSO communities as well as be used for DWSD's overall master planning process.

The first step in the case study analyses was to fully characterize and understand the nature, history, and steps taken to reduce/eliminate SSOs in these areas. This work was done in coordination with local efforts and engineering consultants already working with the case study communities. The SSO tributary areas were delineated in each case study and key sewer pipes were identified, including the SSO pathways.

All six case study communities had flows in excess of their initial design and contract capacity. For most of the case studies, the contract capacity was based on a peak discharge rate of $0.4 \mathrm{cfs}(11 \mathrm{~L} / \mathrm{s})$ per 1,000 people. In some areas, peak flows as high as 10 times the allowable peak discharge rate were occurring. In two case study communities, SSOs occur near the connections to the DWSD interceptor system, as the excessive flows are limited by transport 
capacity to the interceptor. The four additional case study communities have local transport limitations for excessive flows, causing SSOs internal to the local systems. In two of these cases the SSOs are from temporary bypass pumping that is done from manholes in order to relieve or prevent residential basement flooding. All six of the case study communities were interested in obtaining an increase in the contract capacity to the DWSD interceptors as an option for dealing with excessive sanitary sewer flows and to eliminate SSOs.

\subsection{Modeling}

\subsubsection{Characterization of Wet Weather Response}

The approach used in characterizing the wet weather response for separated sewer service areas is based on the approach used in the U.S. EPA's SWMM RUNOFF module. For sanitary areas, RUNOFF determines RDII response volume as the fraction of rainfall that enters a sanitary sewer system during a rainfall event after satisfying the requirements of initial abstraction. The amount of RDII response to a rainfall event is calculated as follows:

where:

$$
\text { RDII Volume }=C(P-V o) A
$$

$$
\begin{aligned}
C= & \text { RDII response factor, } \\
P= & \text { rainfall, } \\
V O= & \text { initial abstraction or amount of rainfall below which } \\
& \text { a response is typically not seen, and } \\
A= & \text { tributary area. }
\end{aligned}
$$

The RDII C factor has been defined as the slope of a best-fit line, which can be estimated by dividing the measured runoff by rainfall minus initial abstraction for a number of selected rainfall events.

In RUNOFF, the initial abstraction is regenerated during dry weather at a rate defined by the DREC (storage recovery) term. This term is required in RUNOFF to simulate multiple rainfall events in a continuous simulation.

During development of Detroit's model, the inflow and infiltration vs. rainfall analysis conducted on the data provided by different communities tributary to the DWSD wastewater collection system revealed that the initial abstraction and RDII terms are seasonally dependent. 
This seasonal dependence is attributed to the groundwater fluctuations due to natural recharge from rainfall and/or snowmelt and in the variation in the evapotranspiration rates throughout the year. With this representation, the wet weather response during dormant conditions will be higher than during the growth conditions, as the initial abstraction is lower and the slope of the response $(\mathrm{C})$ is higher.

The RDII C factor and the initial abstraction, Vo, are the RDII parameters used in RUNOFF to relate total response volumes to the precipitation and the season. Use of this approach allows for an accurate prediction of RDII volumes for other design or actual rainfall events; however, prediction of SSOs also requires estimating the peak flows that are being generated within the system. To quantify how the response volumes are distributed over time into the collection system, up to three triangular unit hydrographs can be defined in RUNOFF as needed to properly represent the actual flow regime. Routines based on this approach were added to RUNOFF in 1993 and are now part of the standard EPA SWMM program.

Parameters used in RUNOFF to describe these triangular unit hydrographs are $\mathrm{T}, \mathrm{K}$, and the fraction of RDII $\mathrm{C}$ applied to each hydrograph. The $\mathrm{T}$ term represents the time from the beginning of each rainfall interval to the peak of the hydrograph and $\mathrm{K}$ is the ratio of the time to recession to the time to peak for the hydrograph. The RDII C is used to determine what fraction of the response is applied to each of the up to three hydrograph defined as part of the response. All three hydrographs have the same starting time for each rainfall interval.

In most cases the $\mathrm{T}$ and $\mathrm{K}$ parameters were determined for only two hydrographs: an inflow (direct response) component hydrograph and an infiltration (delayed response) component hydrograph. Due to lack of a pronounced direct response, some tributary areas were best described by a single hydrograph. Development of these parameters generally involves calibrating the parameters to several selected events. This entire process has been described for the city of Detroit's model (Sherman et al., 1998).

\subsubsection{Estimating SSO Volumes for Case Study Communities}

For the case study communities, a series of design storm events were used for review of existing conditions. The design storms used are:

the 1-month, 24 -h storm $(0.617 \mathrm{in} . / 16 \mathrm{~mm})$;

the $1-\mathrm{y}, 1$-h storm $(1.0 \mathrm{in} . / 28 \mathrm{~mm})$;

the $10-\mathrm{y}, 1-\mathrm{h}$ storm $(1.8 \mathrm{in} . / 46 \mathrm{~mm})$; 
the 1-y, 24-h storm (2.2 in. $/ 56 \mathrm{~mm})$;

the 10-y, 24-h storm (3.6 in./91 mm);

the 25-y, 24-h storm (4.0 in./101 mm); and

the 100-y, 24-h storm (4.7 in./119 mm).

The SWMM models developed for each case study were used to predict the amount of wet weather that would be produced for each of these events.

For the 24-h design storms, the Brater-Sherrill (1975) rainfall distributions were used. The Brater-Sherrill method uses a different rainfall distribution for dormant and growth conditions. All seven design storms were simulated to occur in April and June to account for both dormant and growth conditions, for a total of fourteen simulations.

The city of Center Line was one of the six case study communities and will be used as an example of the procedures followed for local and regional SSO control. According to SEMCOG, Center Line has a population of approximately 8,400 and an employment population of more than 9,100 . The median year of construction for housing in Center Line is 1960 . The SSO tributary area is composed of the entire city (993 acres/404 ha).

All sanitary flow in Center Line passes through a pump station en route to the WWTP in Detroit. However, there is an overflow weir just downstream of the pump station. In certain wet weather conditions when flow exceeds the height of the weir, sanitary flow can overflow into the Lorraine storm drain, which empties into Bear Creek. The Center Line SSO tributary area and SSO pathway are displayed in Figure 8.3.

Flow and rainfall data for the city of Center Line was obtained from the city's engineer. From the daily flow and rainfall data available, nine rain events were studied. For each event, 15-min flow data were used to determine the wet weather volume response. In cases where SSOs occurred, SSO volumes were added to the total as the meter was located downstream of the SSO location.

Two seasons, the dormant and growth seasons, are defined for the Greater Detroit Regional Sewer System (GDRSS) model for all separate sewer service areas. Dormant months are November through April. Growth months are June through September. May and October are defined as transitional months. The rain dependent inflow and infiltration response factors (RDII C factors) were determined by plotting the wet weather volume versus the total rainfall for each event. Best-fit lines were drawn for all the events representing each condition. The initial abstraction was set to 0.15 -in. $(3.8 \mathrm{~mm})$ for dormant conditions and 0.28 -in. $(7.1 \mathrm{~mm})$ for growth conditions. The corresponding RDII C factors were calculated to be $13 \%$ for dormant conditions and $7 \%$ for growth conditions. 


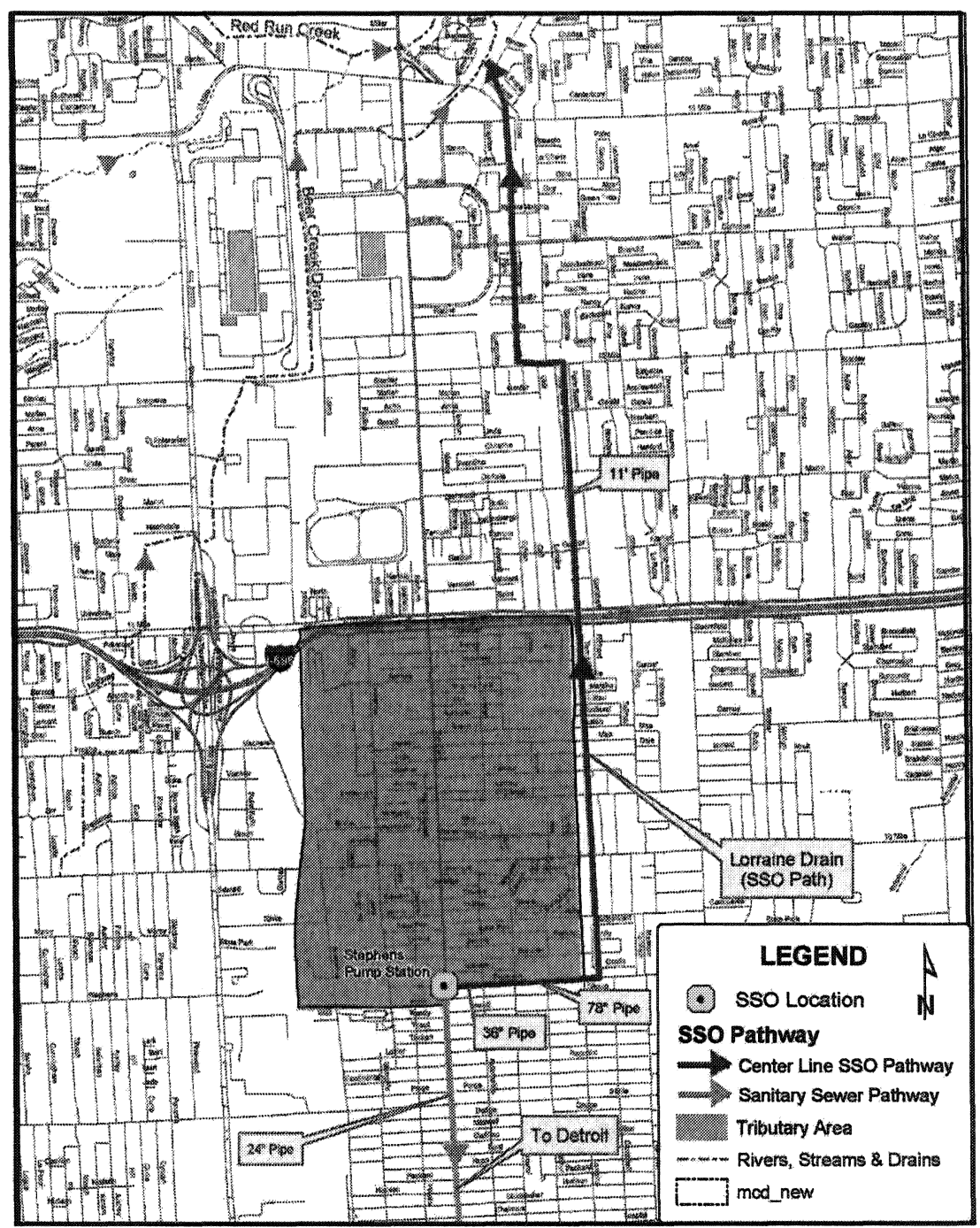

Figure 8.3 Center Line Tributary area and SSO pathway.

The RUNOFF module was used to simulate the wet weather responses for the seven design storm events. RDII response factors and initial abstraction values as defined above were entered into the RUNOFF data file. For the shape of the response, one triangular unit hydrograph, with a time to peak of $4 \mathrm{~h}$ and a recession of $8 \mathrm{~h}$, was found to be sufficient. 
The Extended Transport (EXTRAN) module was used to model the sewer system hydraulics. The three pumps at the pump station were included in the EXTRAN data file. The on-off levels of the pumps were set to field conditions and storage was added to account for in-system storage upstream of the pump station. In order to determine the appropriate amount of in-system storage to include in the model, two storm events from 2001 with known SSO volumes were used.

A profile from the Center Line model as displayed in PC SWMM is shown in Figure 8.4. This shows the sewer downstream of the pump station and the weir overflow being surcharged during the peak of a $25-\mathrm{y}, 24-\mathrm{h}$ design event.

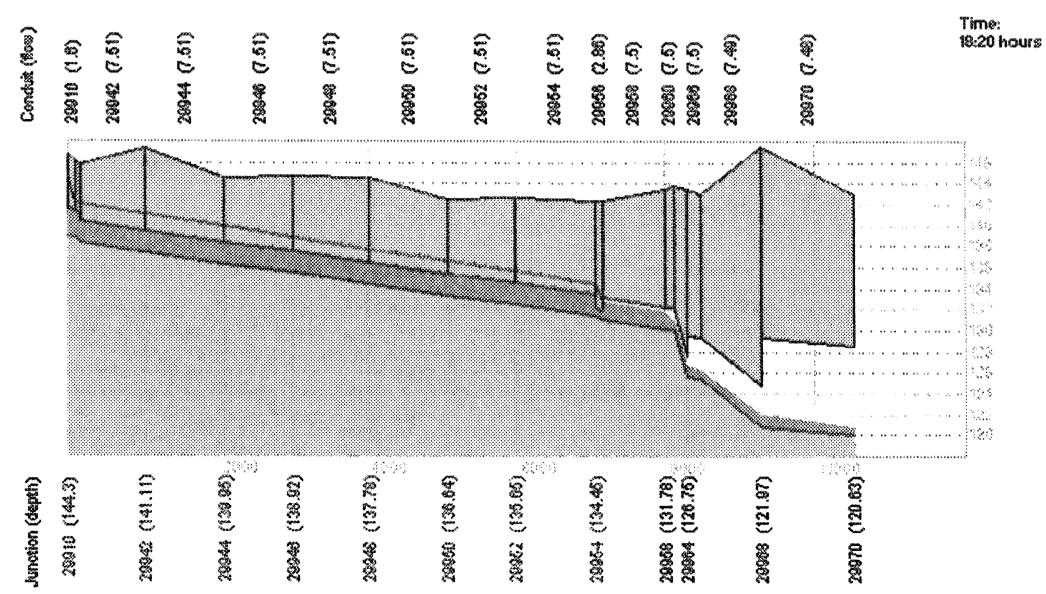

Figure 8.4 Center Line Model under 25-y, 24-h design storm conditions.

Table 8.2 Center Line Design Storm SSO volumes.

\begin{tabular}{lcc}
\hline \multirow{2}{*}{$\begin{array}{c}\text { Design Storm Event } \\
\text { (Rainfall - in./mm) }\end{array}$} & \multicolumn{2}{c}{ Sanitary Sewer Overflow Volume (MG) } \\
\cline { 2 - 3 } & Growth Conditions & Dormant Conditions \\
& & \\
1-month, 24-h (0.62/1.6) & 0.00 & 0.00 \\
1-y, 1-h (1.0/25.4) & 0.00 & 0.00 \\
10-y, 1-h (1.8/45.7) & 0.00 & 0.61 \\
1-y, 24-h (2.2/55.9) & 0.00 & 1.15 \\
10-y, 24-h (3.6/91.4) & 0.76 & 3.00 \\
25-y, 24-h (4.0/101) & 1.06 & 3.51 \\
100-y, 24-h (4.7/119.4) & 1.56 & 4.41 \\
\hline
\end{tabular}


Wet weather volumes, contract exceedance volumes, and SSO volumes were estimated using the model. Center Line has a contract capacity of $6.5 \mathrm{cfs}$ $(184 \mathrm{~L} / \mathrm{s})$ with DWSD, which includes both dry and wet weather flows. Table 8.2 displays the SSO volumes for Center Line from the seven design storms.

\subsection{SSO Control Alternatives}

Three control alternatives were considered for each case study community. Two of these were local alternatives - footing drain disconnection and local storage alternative and one was a regional alternative - transmission of excessive flows to DWSD interceptor system.

\subsubsection{Footing Drain Disconnection}

The footing drain disconnection alternative prevents storm water from reaching the sanitary sewer system by disconnecting the footing drain from the sanitary sewer. A sump pump is installed in each home that has the footing drain disconnected, and the sump pump directs all storm water into a backyard or the storm sewer system. Reducing the volume of water that enters the sanitary sewer system reduces the peak flows in the system during a storm and therefore reduces surcharging. This option reduces or eliminates the need for relief sewers or storage facilities.

Field monitoring of footing drain flows in the regional collection system was conducted using sump pump flow recording. Extrapolations from these results indicate that from $70 \%$ to $90 \%$ of RDII can be attributed to footing drains. For each community, the number of homes with footing drains was estimated. The degree of homeowner participation depends on the design storm and local conditions. In most cases, close to $100 \%$ participation is required in order for footing drain disconnection to be an effective local alternative. In some cases, it was determined that even $100 \%$ participation would not be sufficient to provide needed control of SSOs. In those cases, amount of local storage and associated cost was added to the cost of the option.

The cost of disconnecting footing drains was estimated at US\$6,790 per home, including engineering and construction costs. This estimate was based on ongoing projects in southeast Michigan. It includes sump pump installation, installing a new curb drain along the street that ties into the existing storm system, and installing a new house lead from the sump pump to the new curb drain. 


\subsubsection{Local Storage}

Another local alternative investigated consisted of placing storage basins in the system to temporarily store excessive flows during heavy rainfall events. This would enable peak flows to be reduced downstream of the basins by storing it until the rainfall intensity has been reduced. An advantage of this option is that downstream construction for additional capacity (relief sewers, for example) or the disruption of individual private properties (for footing drain disconnection), which helps to offset its cost. A disadvantage is that the storage basins must be properly maintained and costs associated with the maintenance would have to be assumed by some entity, likely the local service authorities. In addition, access to the basin would be required, and there would be potential for odors to emanate from these facilities.

A cost curve used for estimating storage costs was created based on recent basins constructed in the region. To determine the optimal storage level, continuous simulations were run using $40 \mathrm{y}$ of rain data from Detroit City Airport and the storage volumes calculated for each design storm. The knee of the curve, for both cost and frequency, was determined to be the 25-y, 24-h design storm.

Figure 8.5 displays the local alternative costs for Center Line for the seven events under growth conditions. In the case of Center Line, the storage option was always less than the footing drain disconnection option. However, this was not so for all the case study communities. Generally, it was found that the footing drain disconnection became the cheaper alternative as the size of the design event increased.

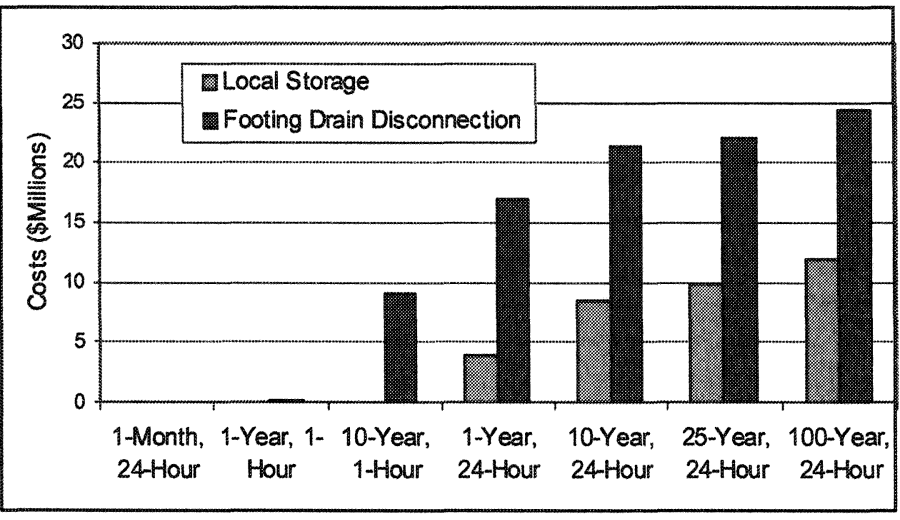

Figure 8.5 Center Line local alternative costs. 


\subsubsection{Regional}

In addition to the local solutions investigated for the six case studies, the feasibility of a regional solution for SSO control was evaluated. This approach for SSO control involves conveying excess wet weather volumes to the DWSD interceptor system for the six case study communities.

The GDRSS Model that had previously been developed by Detroit for analysis of its CSOs was modified to integrate additional details for the six case study communities. These details included any sub-area delineation or additional hydraulic information that was developed in modeling these areas for review of local alternatives. The model was also configured to direct all excess wet weather flow to the regional interceptor system for the six case study communities.

Two events were used for these simulations: the 25-y, 24-h event and the 10-y, 1-h event. The rainfall depths for these events are 4.0 and $1.8 \mathrm{in}$. (101 and $45.7 \mathrm{~mm}$ ), respectively. For the $25-y$ event, an areal reduction factor of 0.91 was used, which resulted in the total rainfall depth being reduced from $4.0 \mathrm{in}$. to 3.6 in. $(91.4 \mathrm{~mm})$.

The regional impacts of accepting these excess flows to the regional system were quantified in terms of changes in the peak hydraulic gradeline (HGL) in the downstream interceptors. Modeled peak HGLs were compared to critical HGLs to determine whether the regional alternative would cause adverse impacts such as basement and street flooding. Critical HGLs were obtained from Detroit's Long-Term CSO Control Plan for major interceptors. A criterion was set that if the modeled HGL is at or above critical HGL under existing conditions, then no more flow can be accepted, no matter how small the additional flow might be. Likewise, if an alternative resulted in the critical HGL being exceeded, then that alternative was not accepted.

Another potential impact of accepting these excess flows to the regional system involves displacement of combined flows. Displacement of combined flows can occur when sanitary flows is discharged to the DWSD combined system, taking up room for other combined flows. The sanitary flow receives treatment, however, CSOs are potentially increased. While this may be acceptable and a net environmental benefit for the short-term, it is anticipated that MDEQ will object to this as a long term solution. Quantification of the magnitude of the displacement proved to not be feasible as the amount of increase in flow introduced to the system by accepting the SSO flows are within the range of the continuity error inherent in the SWMM program used by the GDRSS Model. 
The regional alternative required allowing the communities to discharge above their current contract limits. For four of the communities, the regional option proved to be a viable option as the system was able to absorb these higher flows for both the 10-y event and the 25-y event, . For two of the communities, Center Line and Garden City, the flows could not be accommodated in the downstream interceptors due to the resulting HGLs exceeding the acceptable limits. A regional alternative for Center Line was developed that involved changing their point of discharge to another interceptor that had capacity and was located nearby. The anticipated cost for a regional solution to accommodate the SSO flows for up to a 25-y, 24-h event for Center Line is approximately 12.5 million dollars. This cost included 1.2 million gallons (MG) of storage and 4.6 million in transportation costs to bring flows to the other interceptor. No similar option was available for Garden City.

\subsubsection{Alternative Comparisons}

A comparison of the cost of the alternative control strategies: local storage, footing drain disconnection, and regional, is presented in Figure 8.6 for the 25-y, 24-h event. The results indicate that the optimal solution varies for each community. For two of the communities, local storage is the lowest cost, for one, footing drain disconnection, and for three, the regional approach is optimal.

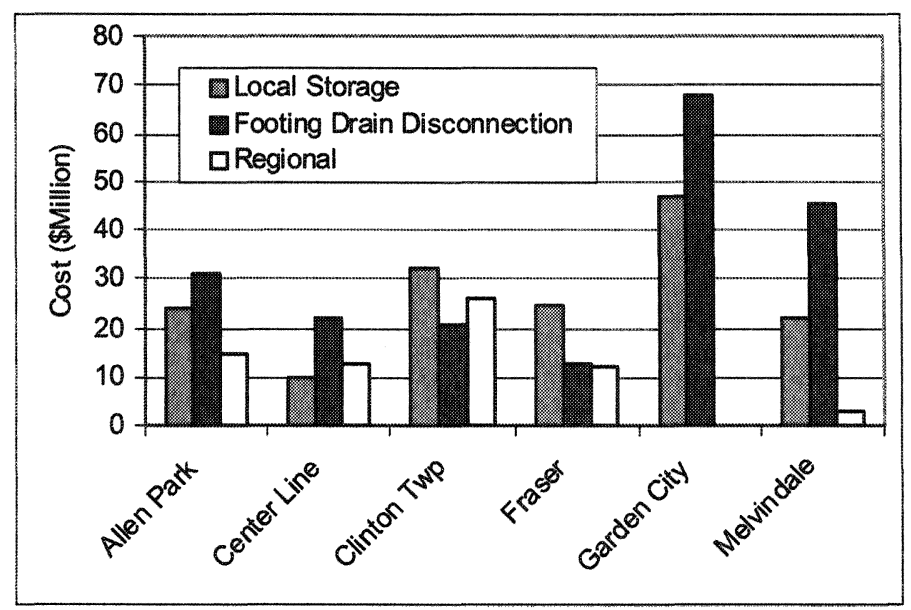

Figure 8.6 Comparison of alternative SSO control strategies (25-y). 


\subsubsection{Discussion}

Even though the regional alternative worked in terms of the regional system hydraulics for five of the case study communities, there are issues such as contractual limits that would have to be addressed. Also, what would be equitable for other communities that might not have SSOs, but they have similar excess RDII and are conveying flows that exceed their contract limits? Additional regional alternatives were simulated that investigated these issues. Based on these additional results, it was determined that in general, the system cannot accommodate flows resulting from a 25-y, 24-h event, but it could accommodate allowable flows generated from the 10-y, 1-h event. Allowable flows are peak flows that can be expected from systems that conforms to criteria for peak hour flow to average daily flow for summer conditions and "best practices for system maintenance" as developed by the WWMP. These best practices are things that should be done to minimize wet weather infiltration/inflow. A partial list of these items includes:

- perform periodic cleaning and televising of sewers to understand condition;

- review manhole structures and have a cross-connection detection program;

- schedule rehabilitation or replacement of defective sections if needed;

- develop ordinance and supporting inspection and enforcement programs for reconnected sump pumps, downspouts, etc.;

- perform periodic flow metering to understand performance and reductions from rehabilitation work

Ultimately, following the best practices for system maintenance should lead to reducing flows to within the maximum peak flow allowed for the 10$\mathrm{y}, 1-\mathrm{h}$ event. The maximum peak flow was developed from a review of flows from 21 communities, and it accounts for the percent of homes with connected footing drains in each community. This approach provided DWSD a equitable framework for setting contract limits for communities coming to DWSD requesting increases in their current contract, one of the impetus for this study.

\subsection{Conclusions}

As a result of the SSO control study, it was concluded that wet weather SSOs in the DWSD system are not primarily the result of limited transport capacity, 
but the result of RDII in excess of original design expectations. Inflows from footing drains was found to be a major causes of excessive RDII, especially from areas developed between 1950 and 1980. In general, it appears that the amount of flow entering systems from footing drains were either underestimated or not properly accounted for when these systems were designed.

Costs for local storage and footing drain disconnections have been developed over the full range of SSO control levels. Local storage costs are generally more cost-effective than footing drain disconnection for smaller design storms (less than the 25-y, 24-h design storm). However, for larger storms, footing drain disconnection is usually more cost-effective. The percent contribution from footing drains of total wet weather inflow and infiltration varies significantly among the communities. For areas with high contributions from footing drains, footing drain disconnection is usually a cost-competitive local alternative.

A number of communities not reporting SSOs or basement flooding were found to have similar excess RDII, but are at a geographical advantage in that their connections to the regional system allows flows that can exceed their contract capacities.

The regional alternatives were evaluated on the basis of their impacts of accepting additional flows to the DWSD system for the six case studies, as well as for other communities/districts. Review of acceptable surcharge levels within the DWSD system provided an objective criterion for determining whether flows can be accepted within the existing system or whether additional improvements would be required. In general, it has been determined that the $25-$ $y$ flows cannot be accepted without causing potential basement flooding and/ or street flooding in the greater Detroit area. CSO displacement and comingling of sanitary sewerage with combined flows are also issues that make it difficult to accept higher level flows due to potential regulatory constraints.

Based on the results of the regional alternatives, it was recommended that DWSD establish an upper bound on contract limits based on an allowable 10$\mathrm{y}, 1-\mathrm{h}$ flow. The allowable 10-y, 1-h flow is the flow generated from a local collection system during the 10-y, 1-h design storm that conforms to criteria for peak hour flow to average daily flow for growth conditions and "best practices for system maintenance" as developed by the WWMP.

Use of a regional solution is anticipated to be allowed as a short-term solution for those communities where these flows can be accepted without adverse impacts downstream. Local SSO solutions such as storage and footing drain disconnection will be needed for flows over the allowable 10-y, 1-h flow up to the level of control that MDEQ established (25-y, 24-h event during 
growth conditions). Communities not reporting SSOs but which are over this contract amount will also need to reduce wet weather flows to meet the allowable 10-y, 1-h flow.

\section{Bibliography}

Anderson Eckstein and Westrick, Inc. City of Center Line Sanitary Sewer System Capacity Analysis and Study (Draft). April 2001.

Brater, Ernest, James Sherrill. Rainfall-Runoff Relations on Urban and Rural Areas. National Environmental Research Center, U.S. Environmental Protection Agency No.670/2-75-046.1975.

Czachorski, Robert and Tobin Van Pelt Inflow and Infiltration Modeling Using System Identification. October 2001.

Hershfield, David. United States Department of Commerce Technical Paper No. 40 Rainfall Frequency Atlas of the United States for Durations from 30 Minutes to 24 Hours and Return Periods from 1 to 100 Years. Not Dated.

Jeng, Kathlie, Michael Bagstad, and James Chung. New Collection System Modeling Techniques Used in Houston. National Conference on Sanitary Sewer Overflows: U.S. EPA, Washington, DC, 1995.

Miles, Wayne and R.E. Tarker, Keith Shirley, and Jason Dorn. How to Defensibly Document I/I Reduction: Two Carolina Success Stories. Water Environment Federation Annual Conference and Exposition: WEF, New Orleans, LA, 1999.

National Sanitation Foundation. Report on Metropolitan Environmental Study Sewerage and Drainage Problems - Administrative Affairs. Report, December 1964.

Sherman, B.J., P. Brink and M.J. TenBroek. 1998. "Spatial and Seasonal Characterization of Infiltration/Inflow for a Regional Sewer System Model." Journal of Water Management Modeling R200-13. doi: 10.14796/JWMM.R200-13.

Swarner, Robert and Michael Thompson. Modeling Inflow and Infiltration in Separated Sewer Systems. National Conference on Sanitary Sewer Overflows: EPA, Washington, DC, 1995.

TenBroek, M.J., G. Fujita, P. Brink, B.J. Sherman and D. White. 1999. "Detroit Water and Sewerage Department Model Extensions and Project Overview." Journal of Water Management Modeling R204-11. doi: 10.14796/JWMM.R204-11.

Vallabhaneni, S., J. Koran, S. Moisio and C. Moore. 2001. "SSO Evaluations: Infiltration and Inflow using SWMM RUNOFF and EXTRAN." Journal of Water Management Modeling R208-12. doi: 10.14796/JWMM.R208-12. 
Walch, Marc, Thomas Christ, Kathleen Leo, Stephanie Ross, and William Brant. Computer Modeling of Sanitary Sewer Overflows Resulting from Peak Flow Conditions. National Conference on Sanitary Sewer Overflows: U.S. EPA, Washington, DC, 1995. 